\title{
COMPARISON OF GLANCING BEHAVIORS OF RIDERS AND DRIVERS AT UNSIGNALIZED INTERSECTIONS INVOLVING RIGHT TURNS
}

Jeffrey Muttart ${ }^{1}$, Wade Bartlett ${ }^{2}$, Sarah Bakhtiari ${ }^{3}$, Tingru Zhang ${ }^{3}$, Siby Samuel ${ }^{3}$, Tracy Zafian ${ }^{3}$, Louis R. Peck ${ }^{4} \&$ Chris Kauderer ${ }^{5}$

${ }^{1}$ Crash Safety Research Center LLC, ${ }^{2}$ Mechanical Forensic Engineering Services, LLC, ${ }^{3}$ University of Massachusetts Amherst, ${ }^{4}$ Dial Engineering LLC, ${ }^{5}$ Kauderer and Associates Email: jmuttart@crashsafetyresearch.com

\begin{abstract}
Summary: The vulnerability of motorcyclists makes them the user group with the highest likelihood of a fatality on roads, a significant proportion of which occur at unsignalized intersections. The current research compares the scanning behaviors of two cohorts of participants at two different intersections involving a right turn. This on-road study included two cohorts: a 'driver-rider' group consisting of 20 participants who were both, licensed to drive and held an endorsement to ride a motorcycle, and a second 'driver-only' cohort comprising 10 participants who only held a driver license. Two types of comparisons were made: the number of anticipatory glances of the driver-rider at the two right intersections, both before and after the intersection, were compared when riding and driving across the same two intersections. Drivers-only completed the test route once while the driverriders navigated the same route once while riding, and a second time while driving, the exact order counterbalanced across all participants. The results showed that driver-rider made significantly more glances to the left when riding compared when driving after the intersection than before, while they made more glances to the right after the entry than before the intersection.
\end{abstract}

Key Words: field study, motorcyclist behavior, driver-rider, anticipation, right turn across path

\section{INTRODUCTION}

Compared to cars and trucks drivers, motorcycle riders are at a higher risk of fatal crashes. Per the report of National Highway Traffic Safety Administration (NHTSA, 2016), motorcycles made up to 3 percent of all registered vehicles in the United States and the fatality rate per rider was 6 times greater than that of all drivers in 2014. On a per-mile base, the number of deaths on motorcycles was over 27 times the number in cars, and motorcyclists were nearly 5 times more likely to be injured compared to drivers. Many of the fatal crashes involving riders occur within intersections or when turning (Muttart et al, 2011). The lack of protection from an enclosed vehicle, the decreased stability due to two wheels of a motorcycle, and the reduced visibility compared to other vehicles have increased the vulnerability of riders.

There is evidence that the awareness of the vulnerability of riders in fact leads to safer behaviors. The study by Hurt et al, (1981) showed that drivers with a family member who rode a motorcycle were less likely to strike a motorcycle when driving a car than were drivers with no motorcycling experience (or family members with such experience). By comparing the crash report of driver-riders and drivers-only between 2007 and 2011, Longthorne et al., (2007) showed that drivers who also rode a motorcycle had $20 \%$ fewer bodily injury claims than drivers 
without a motorcycle endorsement. The increased safety related to the riding experience may be explained by an increased hazard perception performance. Motorcycle riders need to detect a larger number of hazards than car drivers. For instance, while the construction cone is not a direct threat to drivers, it can impact a rider's ability to remain upright. It has been found that motorcyclists respond to hazards faster than inexperienced and experienced drivers (Underwood et al., 2013). By showing that drivers with motorcycling experience were better at hazard anticipation compared to those without motorcycling experience, Horswill and Helman, (2003) found that the hazard perception skills acquired while riding may be transferred to driving. Hosking et al further demonstrated that hazard perception performance of inexperienced riders could benefit from experience as drivers, and also that experienced car drivers could benefit from motorcycling experience (Hosking et al, 2010).

All studies mentioned above have only analyzed the general hazard perception of riders. Given that many fatal crashes involving riders occur within intersections or when turning due to either a driver's or a rider's failure to yield, it is necessary to investigate the anticipatory glances of drivers and riders when entering and negotiating intersections specifically to understand the possible scanning differences between them. One study on this question is the work by (Muttart et al., 2017), where the glance behaviors of three groups (drivers with motorcycling experience while riding, drivers with motorcycling experience while driving, drivers without motorcycling experience while driving) when making left turns were compared. The results indicated that driver-riders executed a greater proportion of glances ahead (toward potential oncoming traffic) while turning left at the stop-controlled intersection compared to the driver-only cohort. No differences were found between the driver-riders in their eye glance behaviors when they were riding or driving. This paper, as a follow-up of (Muttart et al, 2017), further investigated the glances behaviors of the three groups when making right turns at intersections. While right-turn crashes might not be associated with as many crashes, because they require a longer acceleration time in the lane and glances to both the right and left, they offer further insight into the habits of drivers and riders at intersections.

\section{Current study}

A glance toward the next most threatening area between the moment the driver begins traversing into the intersection and before entering the path of conflicting traffic, is a secondary glance. In other words, it is the last-chance for a driver to abort the decision to enter the intersection. Within the framework of Endsley's model of situation awareness, making anticipatory glances and anticipatory speed choices is necessary to achieve the very first level of situation awareness (Endsley, 1995). This research examined the anticipatory glances of drivers and riders when entering and negotiating intersections, as well as the proportion of drivers and riders who make secondary glances before and after the intersection.

In the current on-road study, the performances of two cohorts were assessed. The first cohort involved participants who were both, licensed to drive and held an endorsement to ride a motorcycle (driver-riders). The behaviors of the participants in this cohort were compared when riding and driving over the same roads. The second cohort consisted of participants who only held a drivers' license (drivers-only). The drivers-only drove the same route as the driver-riders 
to examine whether drivers who ride a motorcycle exhibit glancing behaviors both, before and after the entry of intersections that would be consistent with being more attentive.

It is hypothesized that those who ride a motorcycle and appear to be more vulnerable might be more inclined to make secondary glances and full stops before entering intersections. This leads to the two hypotheses.

Hypothesis 1: Driver-riders make more secondary glances while riding compared to when they drive.

Hypothesis 2: Driver-riders make more secondary glances than drivers while driving.

\section{METHOD}

\section{Participants}

There were 30 participants, of which 20 held motorcycle endorsements as well as drivers' licenses. Of the 20 driver-rider, 3 were female riders, 12 normally drive a passenger car and the other 8 drive an SUV or pickup when not on a motorcycle (mean age $=42.9$ years, SD $=11.9$ years; mean years since licensure $=25.9$ years; mean year since motorcycle endorsement $=16.4$ years). The other 10 held a drivers' license and were not motorcyclists, nor did they hold a motorcycle endorsement. There were 2 female drivers (mean age $=34.3$ years, $\mathrm{SD}=14.7$ years; mean years since licensure $=17.1$ years). This study had approval from the University of Massachusetts Amherst Institutional Review Board.

\section{Equipment}

Each driver-rider used his or her own motorcycle. There were 2 cruisers, 1 dirt bike, 8 touring motorcycles, and 7 sport motorcycles. The car used for the experiment was a 2008 Honda Accord four-door sedan. The car and each motorcycle were affixed with a video V-Box system. The two video cameras were aimed forward and left and forward and right which allowed a range of approximately 120 field of view.

Each driver and rider wore ASL MobileEye eye tracking glasses. The eye tracking glasses had two cameras, one designed to record eye movement, and the other designed to record the forward (world) view. The MobileEye software and calibration process integrates the view from each camera and produces a video that shows a crosshair overlaid on the forward view. The crosshair represents where in the forward view, the driver was scanning at any time. The eye tracker has an accuracy of about 05 degrees of visual angle. All riders wore special helmets of customizable size, with a visor that allowed for the eye tracking glasses to be worn without interference (Figure 1). 


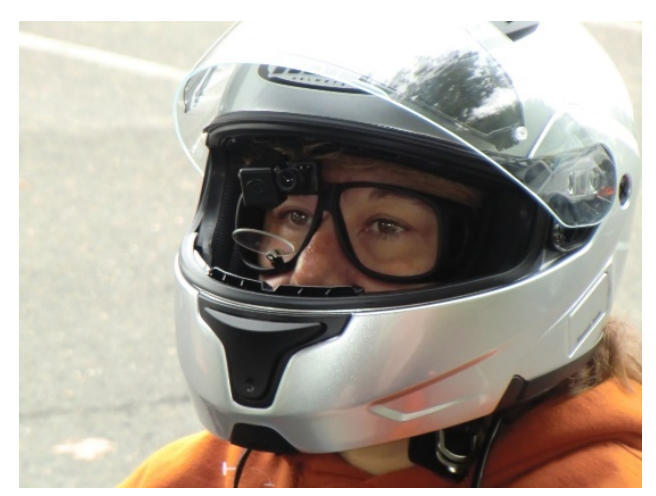

Figure 1. The ASL MobileEye eye tracking system worn under the helmet and visor

\section{Test Route and Experimental Design}

There was a pre-defined route that each driver-only and driver-rider navigated. The route was selected to assure that each driver and rider experienced curves, left turns, right turns, and through movements. The route was in the towns of Hadley and Amherst, Massachusetts. In the entire route, each driver and rider made three left turns across oncoming traffic, traveled straight through two intersections, and made two right turns at intersections without traffic signals. Anticipatory glance and speed behaviors were recorded during the approach to, and departure from the stop line, or the start of the turn. The present study focused only on anticipatory glance behavior for the two right-turn routes (Massachusetts Avenue and Rotary Street; see Table 1). The riding or driving order is counterbalanced for the 20 driver-rider participants.

Table 1. Scenario Views for Right Turn across Path (LTAP) scenarios used in the study.

\begin{tabular}{|l|l|l|}
\hline Street Name & Street Description & $\begin{array}{c}\text { Intersection View } \\
\text { (Source: Google Street View, } \\
\text { 2015) }\end{array}$ \\
\hline $\begin{array}{l}\text { Lincoln Avenue, } \\
\text { right turn onto } \\
\begin{array}{l}\text { Massachusetts } \\
\text { Avenue }\end{array}\end{array}$ & $\begin{array}{l}\text { This intersection is located in the middle of the } \\
\text { University of Massachusetts - Amherst campus. Lincoln } \\
\text { Avenue is a residential street. Massachusetts Avenue is a } \\
\text { two way median divided street connecting campus } \\
\text { destinations. The right turn is onto a divided street where } \\
\text { the traffic flows to the right. }\end{array}$ \\
\hline $\begin{array}{l}\text { North Pleasant } \\
\text { right turn onto } \\
\text { Governors Drive }\end{array}$ & $\begin{array}{l}\text { The intersection is located on the north end of the } \\
\text { yniversity of Massachusetts-Amherst campus. There are } \\
\text { four connecting streets, each with two lanes. The right } \\
\text { turn takes vehicles down a hill past academic buildings. }\end{array}$ & \\
\hline
\end{tabular}

\section{Procedure}

After reading and signing an informed consent, each driver or rider was asked to drive the test route in the car. Each participant drove the route until they gained complete familiarity. Upon returning from practicing the route, each participant was outfitted with an eye tracker. Each driver-rider drove or rode first, then returned to the command center. After returning from the first drive or ride, the participant was escorted to his or her motorcycle, or to the car. For those who were drivers-only, the experiment ceased after a single experimental drive. 


\section{Dependent variable}

The present study focused only on anticipatory glance behavior for both cohorts. The glances towards the left, right and across the intersection were analyzed separately. Both, drivers and riders' anticipatory glances were compared at two right turns. Anticipatory glances are defined as glances toward the area of the next greatest conflict at a time after crossing the stop line, or after crossing the end of the double yellow center line. For the right turns, an anticipatory secondary glance was a glance to the left, across or right, after crossing the stop line (after $=0$ and before $=$ 1). The stop line verification process was performed with the eye tracking video and the scorer would then work back 3 seconds from that point with the eye tracking video. Using frame-byframe analysis of the video, the blind scorer recorded glances toward the left, the right, or ahead. Glances were divided into half-second time bins. In this experiment, the anchor location from which all glance measurements were taken was the stop line or yield line.

\section{RESULTS}

The number of anticipatory glances across time were aggregated into two groups, preintersection ( $-3<=\mathrm{t}<0$ seconds) and post-intersection $(0<=\mathrm{t}<=3$ seconds) and analyzed both, within the driver-rider group and between the driver-rider and the drivers-only groups separately. Glances towards the left, right and across were also analyzed separately.

The glance count data were submitted to a 2 x 2 × 2 mixed-factor Bayesian analysis with Group as a between-subject factor and Scenario (Intersection vs. Roundabout) and Time (Pre-vs. Post) as within-subject factors. We employed default Bayesian tests (Rouder \& Morey, 2012) instead of null-hypothesis significance tests. Bayes factors are the measure of evidence for an effect of interest, reported as B10. Bayes factors are ratios of likelihood of the obtained data favoring a model including an effect of interest to that excluding the effect. Bayes factors below 3 mean only "anecdotal" evidence for an effect, indicating that data are indifferent between the two competing models while those greater than 3 indicate that data have strong evidence for the presence of the effect, and greater values of Bayes factors indicate greater evidence for the effect. Terminologies for describing the magnitude of each effect come from (Jeffreys, 1961).

\section{Glances towards the right}

Glancing behavior between the driver-rider and driver groups: Data gave substantial evidence for the Scenario by Time interaction $[\mathrm{F}(1,28)=14.01, \eta 2=.30, \mathrm{~B} 10=8.79]$. Post-hoc analysis indicated that participants made substantially more glances before than after the entry to the roundabout [paired-samples t $(29)=2.94, \mathrm{~B} 10=6.63$ ] but not in the Intersection scenario [paired-samples t $(29)=2.39, \mathrm{~B} 10=2.23$ ]. The data did not give substantial evidence for the remaining effects [all $\mathrm{B} 10<1.84$ ].

Glancing behavior within the driver-rider group: Riders made more glances to the right after the entry than before $\left[F(1,19)=27.70, \eta^{2}=.59, B_{10}=6.9 \times 10^{2}\right]$, a difference substantially more pronounced in the Intersection than the Roundabout scenarios $\left[F(1,19)=5.05, \eta^{2}=.21, B_{10}=\right.$ 8.03]. Data gave no substantial evidence for the remaining effects [all $B_{10}<2.55$ ]. 


\section{Glances towards the left}

Glancing behavior between the driver-rider and driver groups - Similarly, with their glances to the right, participants made substantially more glances to the left before than after the entry [F (1, $28)=13.60, \eta 2=.30, \mathrm{~B} 10=8.79$ ] only in the Roundabout scenario [paired-samples $\mathrm{t}(29)=2.94$, $\mathrm{B} 10=6.63$ ] but not in the Intersection scenario [paired-samples $\mathrm{t}(29)=2.39, \mathrm{~B} 10=2.23$ ]. The remaining effects were not substantial [all B10<1.85].

Glancing behavior within the driver-rider group - Participants made decisively more glances when riding a motorcycle than when driving a car $[\mathrm{F}(1,19)=4.40, \eta 2=.17, \mathrm{~B} 10=1.7 \times 104]$. They glanced to the left decisively more frequently before than after the entry to the roundabout/intersection $[\mathrm{F}(1,19)=.86, \eta 2=.04, \mathrm{~B} 10=1.4 \times 104]$, and the effect of Time was greater when driving a car than when riding a motorcycle $[\mathrm{F}(1,19)=42.89, \eta 2=.69, \mathrm{~B} 10=6.4$ $x$ 104]. Data did not indicate substantial evidence for the other effects [all B10<.91].

\section{Glances across the intersection}

Glancing behavior between the driver-rider and driver groups - Data gave substantial evidence against all the main effects $\left[1 / 10<B_{10}<1 / 5.91\right]$ and strong to decisive evidence against all the interaction effects $\left[1 / 111.11<B_{10}<1 / 12.34\right]$.

Glancing behavior within the driver-rider group - Data gave substantial to decisive evidence against all the effects $\left[1 / 500<B_{10}<1 / 6.57\right]$.

\section{DISCUSSION}

The current research evaluated the anticipatory glance behaviors of two groups of participants (a driver-rider and a driver-only) at two unique unsignalized right-turn intersections and examined two primary hypotheses. It was found that diver-riders made significantly more glances to the left when riding compared to when driving, providing support for hypothesis 1 . When turning right, the major threats come from the left and due to the vulnerability of the riders, they pay more attention to the left. The results indicated that there was not a significant difference between glancing behavior (either left, right or across) of the driver-rider cohort and driver-only cohort when driving and therefore hypothesis 2 was not supported.

Post hoc analyses showed that for the Roundabout scenario, significantly more number of glances occurred before the entry to intersection, than immediately after. Further, it was also observed that the riders glanced to the left more frequently than the drivers before than after the intersection, while they were found to exhibit the opposite pattern while glancing right. Our results do not indicate any transfer of the hazard anticipation skill of the driver-riders from their riding to their driving. This finding is inconsistent with the results reported by Horswill and Helman who show that car drivers with motorcycling experience showed better hazard anticipation performance compared to those without motorcycling experience (Horswill \& Helman, 2003). One possible explanation might be the differences in the hazard perception tests used in the two studies. 
The current on-road study has some limitations. First, we did not consider age and experience which may play moderating effects on rider and driver behaviors. Second, we have only tested our hypothesis based on two different right turn scenarios. Further studies should integrate vehicular data (e.g. speed, steering angle) for a better understanding of participants' response to hazards after they scan for them.

In summary, this on-road experiment illustrated the difference between the anticipatory glance behaviors of driver-riders and riders when turning right at unsignalized intersections. Accordingly, there is some potential for the development of training programs targeted at improving driver and rider behaviors. Potential engineering countermeasures require further research to corroborate our findings from the current study and Muttart et al., 2017.

\section{REFERENCES}

Endsley, M. R. (1995). Toward a theory of situation awareness in dynamic systems. Human Factors: The Journal of the Human Factors and Ergonomics Society, 37(1), 32-64.

Horswill, M. S., \& Helman, S. (2003). A behavioral comparison between motorcyclists and a matched group of non-motorcycling car drivers: factors influencing accident risk. Accident Analysis \& Prevention, 35(4), 589-597.

Hosking, S. G., Liu, C. C., \& Bayly, M. (2010). The visual search patterns and hazard responses of experienced and inexperienced motorcycle riders. Accident Analysis \& Prevention, 42(1), 196-202.

Hurt, H.H. Jr., J.V. Ouellet, and D. R. Thom. (1981) Motorcycle Accident Cause Factors and Identification of Countermeasures (DOT HS 805 862). National Highway Traffic Safety Administration. Washington, DC.

Jeffreys, H. (1961). Theory of Probability (3rd ed.). Oxford, UK: Oxford University Press.

Longthorne, A., Varhese, C. Shankar, U. (2007). Fatal Two-Vehicle Motorcycle Crashes (DOT HS 810 834). National Highway Traffic Safety Administration. Washington, DC.

Muttart, J., Peck, L., Guderian, S., Bartlett, W., Ton, L., Kauderer, C., \& Manning, J. (2011). Glancing and stopping behavior of motorcyclists and car drivers at intersections.

Transportation Research Record: Journal of the Transportation Research Board, 2265, 8188.

Muttart, J., Bartlett, W., Peck, L. R., Zafian, T., Yamani, Y., Fisher, D. L., Dinakar, S. (2017). Motorcyclists' Glance Behaviors at Unsignalized Intersections - Left Turn across Path. In Proceedings of the Annual Transportation Research Board Meeting.

National Highway Traffic Safety Administration. (2016). Traffic Safety Facts, 2014: Motorcycles. (Report no. DOT HS-812-292). Washington, DC: Department of Transportation.

Rouder, J. N., \& Morey, R. D. (2012). Default Bayes factors for model selection in regression. Multivariate Behavioral Research, 47, 877-903.

Underwood, G., Ngai, A., \& Underwood, J. (2013). Driving experience and situation awareness in hazard detection. Safety Science, 56, 29-35. 